\title{
Possible Protective Role of Selenium on Testicular Toxicity Induced by Bisphenol A in Adult Male Albino Rats: Histological and Immunohistochemical Study
}

A.M.Ali, S.A.Shalaby, G.M.M.Abosaif and E.A.EI Banna

Anatomy \&Embryology, Dept., Faculty of Medicine, Benha Univ., Benha, Egypt

E-mail: gehad.saif25@yahoo.com

\begin{abstract}
Background: Bisphenol A (BPA) is an endocrine disrupting chemical that predisposes to reproductive toxicity due to its oxidative stress. Selenium (Se), found in cereals, fish, and meat and has antioxidant properties. The aim of this work is to investigate the harmful effect of exposure to BPA on the testes of adult male albino rats and the protective effect of Se. Material\& methods: This study included 40 adult male albino rats were divided equally into 4 groups: Group I (control group) It received distilled water once daily by gastric tube for 4 weeks. Group II (Selenium group) It received $10 \mu \mathrm{g}$ Se $/ \mathrm{kg}$ bw/day; administered orally via gastric tube for 4 weeks. Group III (BPA group) It received 10 $\mu \mathrm{g} \mathrm{BPA} / \mathrm{kg}$ bw/day; administered orally via gastric tube for 4 weeks. Group IV (BPA+Se group) It received $10 \mu \mathrm{g}$ $\mathrm{BPA} / \mathrm{kg}$ bw/day followed by $10 \mu \mathrm{g}$ Se $/ \mathrm{kg}$ bw/day. Both administered orally via gastric tube for 4 weeks. The sections of testis were stained with Hematoxylin \& Eosin and Masson's Trichrome stains, Also Immunohistochemical study was done to detect BCL2. RESULTS: The study had demonstrated that BPA caused degeneration in the seminiferous epithelium and in the interstitium, dilitation and congestion of the blood vessels, and increased of the collagen fibers in the interstitium. Immunohistochemical results showed a decrease in the expression of the antiapoptotic protein (Bc12).Selenium administration caused significant improvement in the histological structure of the testis. Conclusion: selenium protects the testis from the toxic effect of Bisphenol A.
\end{abstract}

Keywords: Bisphenol A, Selenium, Testis.

\section{Introduction}

Background: Because of the oxidative stress it causes, bisphenol A (BPA) is a reproductively hazardous endocrine disruptor. There are several foods that contain Selenium (Se), which has anti-oxidant qualities. It is the purpose of this study to examine the detrimental effects of BPA exposure on the testes of adult male albino rats and the protective effects of Se. Methods and materials: A total of 40 adult male albino rats took part in this research, which was split into four equal groups: For four weeks, Group I (the control group) was fed distilled water via a stomach tube. Group II (Selenium group) was given $10 \mathrm{~g} \mathrm{Se} / \mathrm{kg}$ bw/day through stomach tube for four weeks. It was delivered orally via gastric tube for four weeks to Group III (the BPA group), which got $10 \mathrm{~g} \mathrm{BPA} / \mathrm{kg}$ bw/day. There were two treatments for Group IV (the $\mathrm{BPA}+$ Se group): first, 10 micrograms of $\mathrm{BPA} / \mathrm{kg}$ body weight per day, followed by 10 micrograms of selenium $/ \mathrm{kg}$ body weight per day. For a total of four weeks, both medications are taken orally via a gastrostomy tube. Hematoxylin and eosin, Masson's trichrome, and an immunohistochemical investigation were used to identify BCL2 in the testis. The research found that BPA induced degeneration of the seminiferous epithelium and the interstitium, dilation and congestion of the blood vessels, and a rise in collagen fibres in the interstitium. Anti-apoptotic protein expression was reduced by immunohistochemical analysis $(\mathrm{Bcl} 2)$. The histological structure of the testis improved significantly after selenium therapy. Bisphenol A has a harmful impact on the testis, although selenium protects it.

\section{Aim of the work}

This work was aimed to investigate the toxic effects of BPA on the testis of adult male albino rats and to investigate the possible protective effects of selenium on these toxic effects.

\section{Material and methods}

\section{A) Materials:}

Animals:

Experimentation was carried out on forty 8-12week-old male albino rats (weighing 200-220 grammes). Experiment animals were procured from Vacsera, a Helwan, Egypt-based holding firm for biological goods and vaccinations, and housed in the Faculty of Medicine, Benha University's experimental animal section. The rats were kept at 22-25oC with three rats per cage with tap water and commercial diet available throughout the day. All of the rats were housed in the identical conditions throughout the study.

\section{Chemicals:}

1-Bisphenol A (BPA):

The chemical was obtained from LOBA Chemie, Pvt. Ltd. 107, Wodehouse Road, Mumbai 400005 India. The connection with this company was through LEC Company for chemicals in Benha.

\section{2-Selenium (Se):}

It was used in the form of sodium selenite ( $\mathrm{Na} 2$ $\mathrm{SeO} 3$ ). This compound was obtained from Sigma Chemicals Co. (Sigma, St. Louis, USA).

B) Experimental design:

40 adult male albino rats were used in this study. The rats were divided into 4 groups, 10 rats in each group $(n=10)$.

Group I (control group) It received distilled water once daily by gastric tube for 4 weeks. 
Group II (Selenium group) It received $10 \mu \mathrm{g} \mathrm{Se}$ $/ \mathrm{kg}$ bw/day; administered orally via gastric tube for 4 weeks.

Group III (BPA group) It received $10 \mu \mathrm{g}$ BPA /kg bw/day; administered orally via gastric tube for 4 weeks (Al-Amoudi, 2018).

Group IV (BPA+Se group) It received $10 \mu \mathrm{g}$ $\mathrm{BPA} / \mathrm{kg}$ bw/day followed by $10 \mu \mathrm{g}$ Se $/ \mathrm{kg}$ bw/day. Both administered orally via gastric tube for 4 weeks (Al-Amoudi, 2018).

At the end of four weeks, the animals were slaughtered under anaesthetic with gentle ether inhalation, and their testicles and scrotum were opened and removed. The testes were then placed in $10 \%$ neutral buffer formalin and incubated for 24 hours. In order to preserve the samples, they were placed in paraffin. Hematoxylin and eosin, Masson's trichrome, and BCL2 immunohistochemical staining were performed on paraffin slices 5-7 $\mathrm{m}$ thick placed on glass slides. In the Anatomy and Embryology Department of the Benha Faculty of Medicine, Benha University, sections were taken using a digital camera coupled to a microscope (Axioskop MRc5; Carl Zeiss, Oberkochen, Germany). Image $\mathbf{J}$ software was used to quantify the mean area percentage of collagen fibres (in Masson's trichrome stained sections) and the mean area percentage of Bcl-2 immuno-expression (in Bcl-2 stained sections). The findings were statistically analysed.

Statistical analysis:

was performed using one-way analysis of variance (ANOVA) test by using computerized Statistical Program for Social Sciences (SPSS program) version 23 to detect significant differences between the studied groups.

\section{Results}

Histological Examination of H\&E stained sections: Group I (control group)

Revealed normal structure of seminiferous tubules separated by interstitial tissue. The seminiferous tubules appeared as rounded or oval in shape, surrounded by a thin basal lamina, densely packed with germ cells and Sertoli cells and nearly of the same diameter. Each tubule was lined with a complex stratified germinal epithelium that was composed of well-arranged layers of spermatogenic cells including spermatogonia, primary spermatocytes, secondary spermatocytes, spermatids, and sperms as they are arranged from the basal lamina to the seminiferous tubule lumen. (Fig1, 2)

\section{Group II (Selenium group)}

There were no histological differences detected between this group and the control group. (Fig 3, 4)

\section{Group III (BPA group)}

There was degeneration in the seminiferous epithelium, the seminiferous tubule lumen showed apparent decrease in sperms population (nearly empty from mature sperms) and necrotic germ cells were seen in the center of the tubules. There was also separation (shedding) of the germinal epithelium.The interstitial tissue showed vacuoles, intertubular hemorrhage and the blood vessels appeared dilated and congested. (Fig $5,6,7$ )

\section{Group IV (BPA+Se group)}

Showed significant improvement in the histological structure of the testis and the architecture of seminiferous tubules are nearly similar to normal. The seminiferous tubules have densely packed and lined with intact stratified germinal epithelium and no degeneration was seen. The seminiferous epithelium appeared adherent to the basal laminae and no separation was seen. Spermatogenic cells of the seminiferous tubules shown all stages of spermatogenesis .The interstitial tissue appeared with average size and the dilated and congested blood vessels were not found in this group and the vacuoles were not seen also. (Fig 8, 9)

\section{The Masson's trichrome stained sections:}

There was a significant increase in the collagen fibers deposition in the interstitium of the BPA group when compared with control group, Se group and Se+BPA group. (Fig 10, 11, 12, 13)

The Bcl-2 immunohistochemical stained sections:

There was asignificant decrease in the Bcl-2 immuno-expression in the BPA group when compared with control group, Se group and Se+BPA group. (Fig 14, 15, 16, 17)

Histomorophometrical results:

1) Mean area percentage of collagen fiber deposition by Masson's trichrome staining was represented in (Table 1 \& Histogram 1)

There was a significant increase in the mean area percentage of collagen fibers deposition $(\mathrm{P} \leq 0.05)$ in the BPA group as compared to control group and $\mathrm{Se}$ group.

There was a significant decrease in the mean area percentage of collagen fibers deposition $(\mathrm{P} \leq 0.05)$ in the BPA +Se group as compared to BPA group.

There was no significant difference of collagen fibers deposition $(\mathrm{P} \geq 0.05)$ in the BPA + Se group as compared to control group and Se group.

2) Mean area percentage of BCL2 immunoexpression was represented in (Table 2 \& Histogram 2)

There was a significant decrease in the mean area percentage of Bcl-2 immuno-expression $(\mathrm{P} \leq 0.05)$ in the BPA group as compared to control group and Se group.

There was a significant increase in the mean area percentage of Bcl-2 immuno-expression $(\mathrm{P} \leq 0.05)$ in the BPA +Se group as compared to BPA group.

There was no significant difference in the mean area percentage of Bcl-2 immuno-expression $(\mathrm{P} \geq 0.05)$ in the BPA + Se group as compared to control group and Se group. 


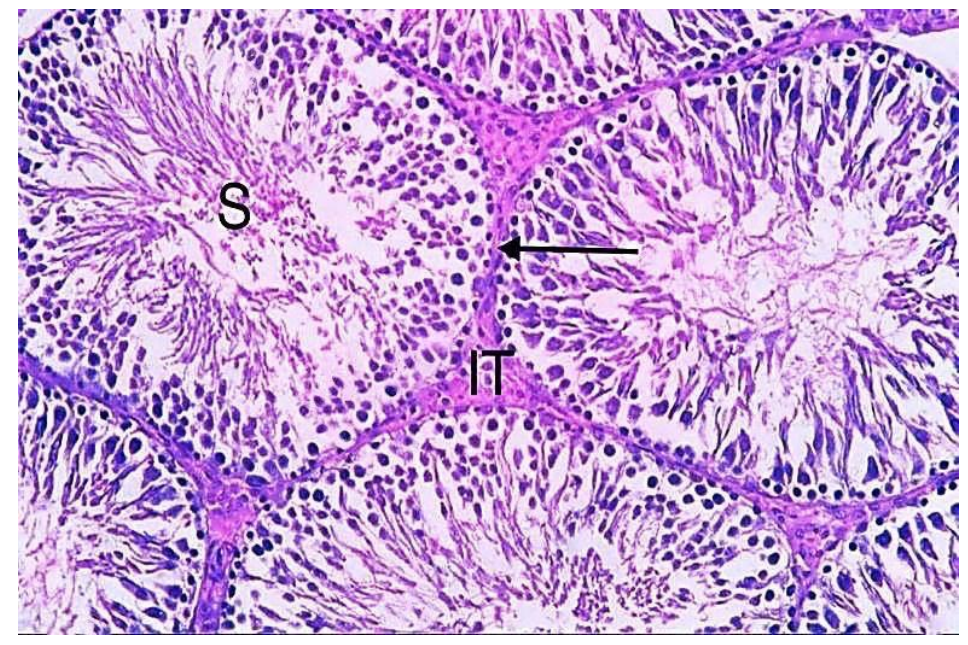

Fig. (1) A photomicrograph of section of adult control rat testis (Group I) showing: normal testicular tissue .Normal seminiferous tubules (Black arrow) densely packed with spermatogenic cells, the lumen is filled with flagella of mature sperms (S) with normal interstitial tissue (IT) in between. (H and E X200)

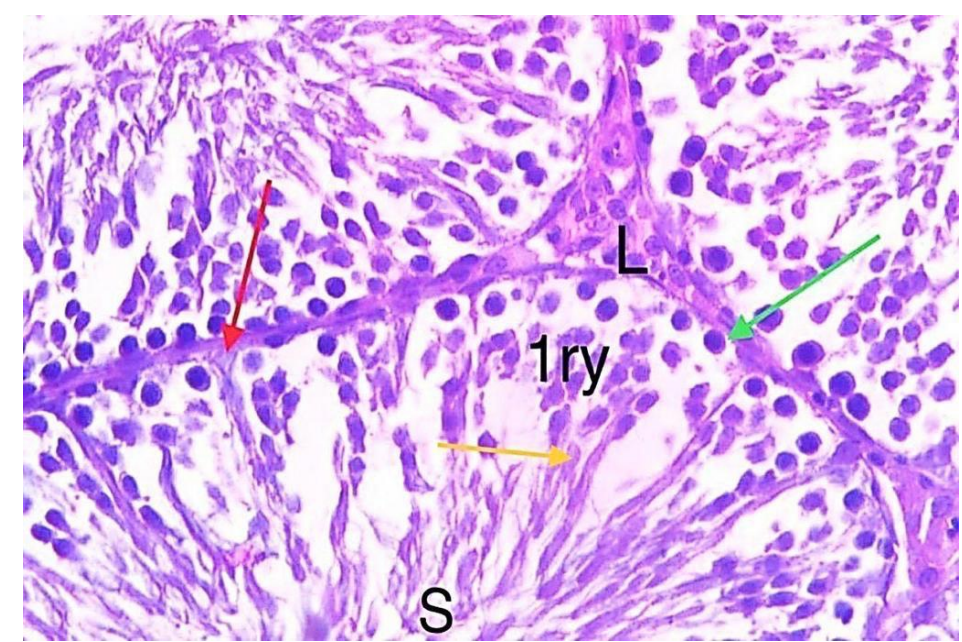

Fig. (2) A photomicrograph of section of adult control rat testis (Group I) showing: parts of adjacent seminiferous tubules with interstitial tissue in between them. The seminiferous tubule contains sertoli cell (red arrow),Spermatogonia (green arrow) resting on basal lamina, primary spermatocyte (1ry), spermatozoa (S), Multiple normal Leydig cells with oval or rounded nuclei and acidophilic cytoplasm (L) in the interstitial tissue in between the seminiferous tubules .(H and E X400)

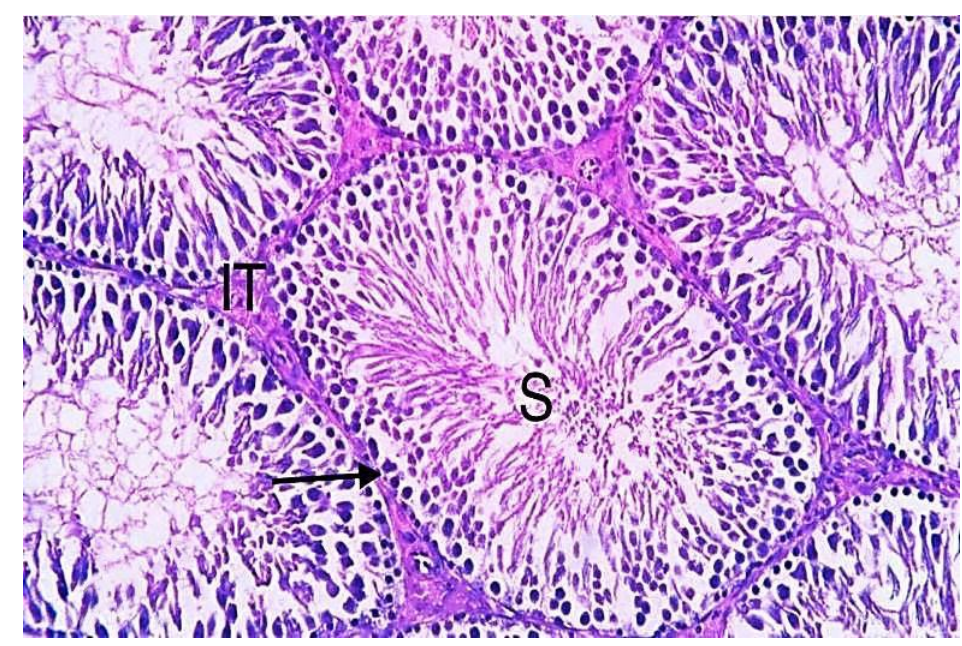

Fig. (3) A photomicrograph of section of adult rat testis of Se group (Group II) showing: the same histological picture as the control group. (H and $\mathbf{E} \mathbf{X 2 0 0}$ ) 


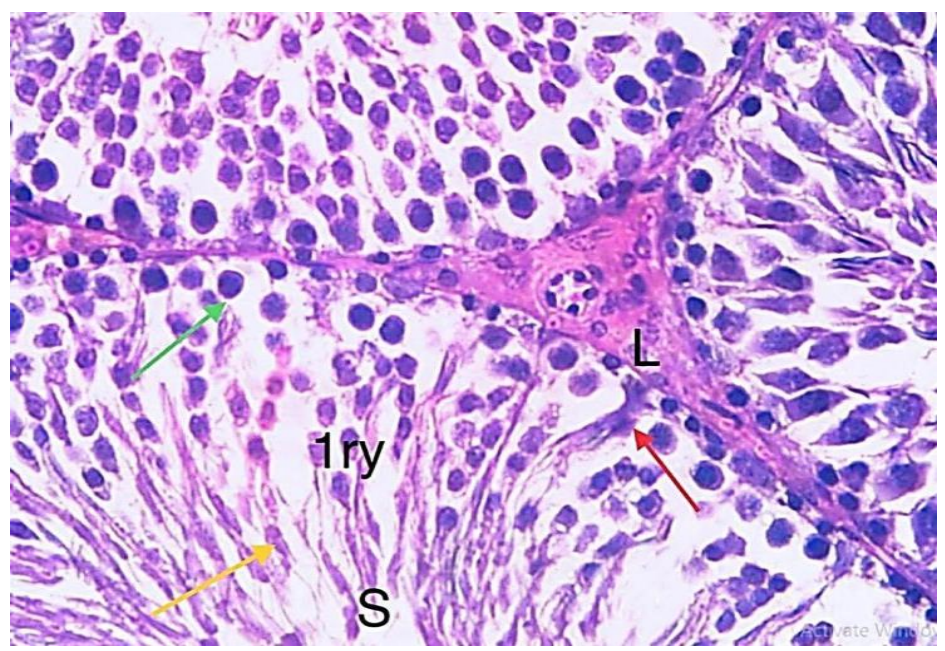

Fig. (4) A photomicrograph of section of adult rat testis of Se group (Group II) showing: the same histological picture as the control group. (H and $\mathbf{E} \mathbf{X 4 0 0}$ )

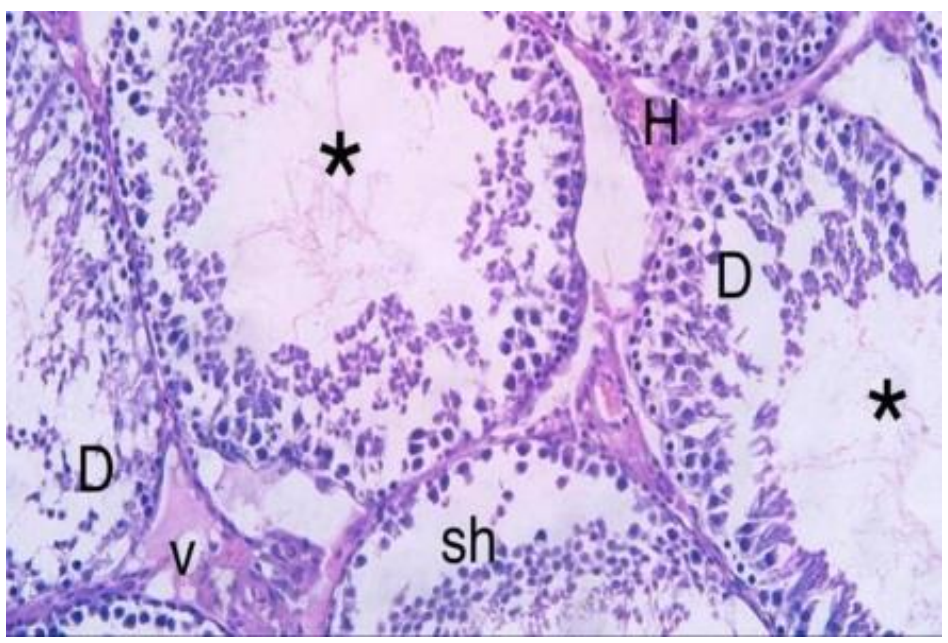

Fig. (5) A photomicrograph of section of adult rat testis of BPA group (Group III) showing: destruction in the testicular tissue .The seminiferous tubule lumen is nearly empty from mature sperms (*), degeneration (D) in the seminefrous epithelium between the spermatogenic cells, shedding in the seminefrous epithelium (Sh), vaculations (v) and exudate fluid $(\mathrm{H})$ in the interstitial tissue. (H and E X200)

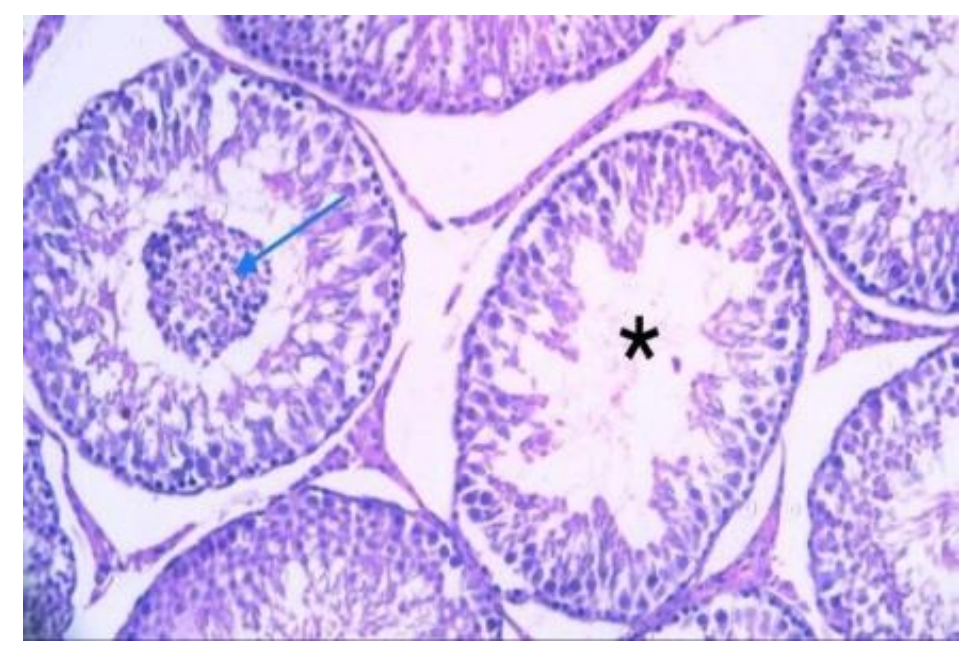

Fig. (6) A photomicrograph of section of adult rat testis of BPA group (Group III) showing: The seminiferous tubule lumen is nearly empty from mature sperms $(*)$, desquamated germ cells in the center of the tubule (blue arrow) and nearly the diameter of the tubules is decreased.(H and E X200) 


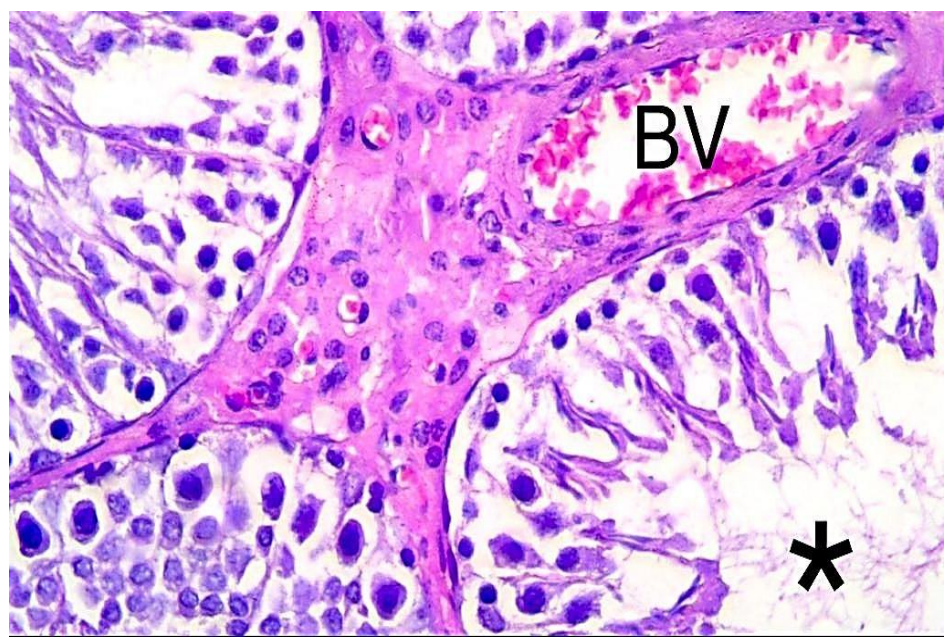

Fig. (7) A photomicrograph of section of adult rat testis of BPA group (Group III) showing: The seminiferous tubule lumen is nearly empty from mature sperms The seminiferous tubule lumen is nearly empty from mature sperms $(*)$, seminiferous tubule with degeneration (D) in the seminefrous epithelium between the spermatogenic cells, dilated and congested blood vessel in the interstitium between the tubules (BV).(HandEX400)

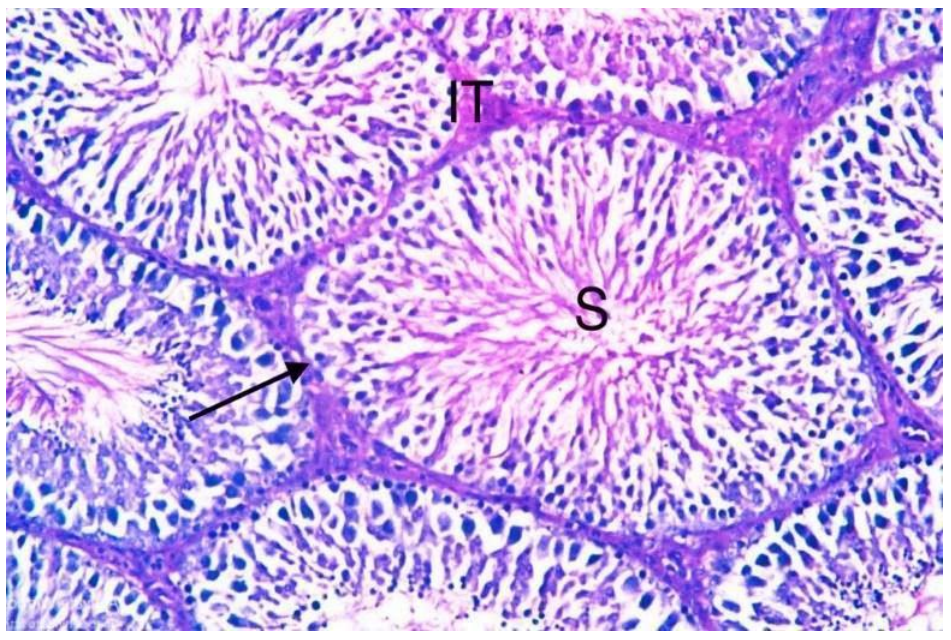

Fig. (8) A photomicrograph of section of adult rat testis of BPA +Se group (Group IV) showing: apparently normal seminefrous tubules similar to control group (Black arrow) densely packed with spermatogenic cell and, the lumen is filled with spermatozoa (S) with normal interstitial tissue (IT) inbetween. (H and E X200)

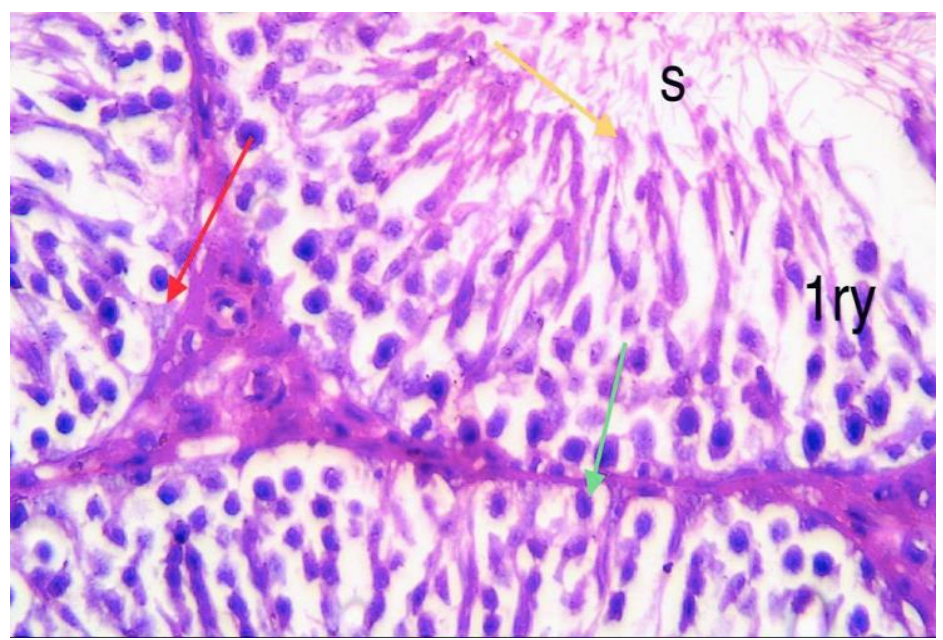

Fig. (9) A photomicrograph of section of adult rat testis of BPA +Se group (Group IV) showing : apparently normal seminefrous tubule similar to control with interstitial tissue inbetween which contain leydig cells (L), The seminiferous tubule contains sertoli cell (red arrow),Spermatogonia (green arrow) resting on basal lamina, primary spermatocyte (1ry), spermatozoa (S) .(H and E X400) 


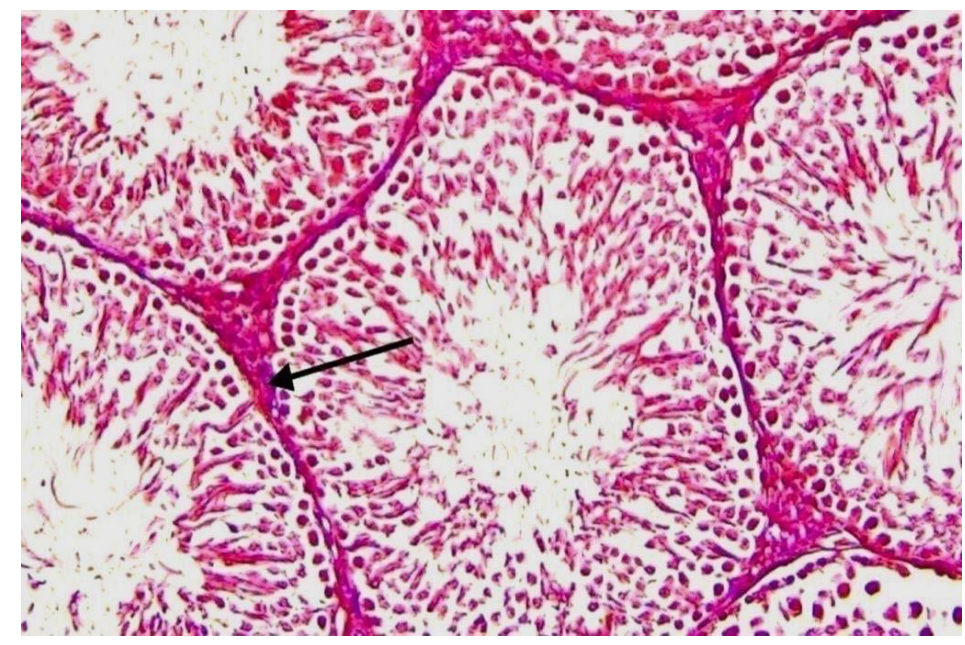

Fig. (10) A photomicrograph of section of adult control rat testis showing: few amount of collagen fibers in the interstitial tissue between the seminefrous tubules which appear blue in color (black arrow). (Masson trichrome x200).

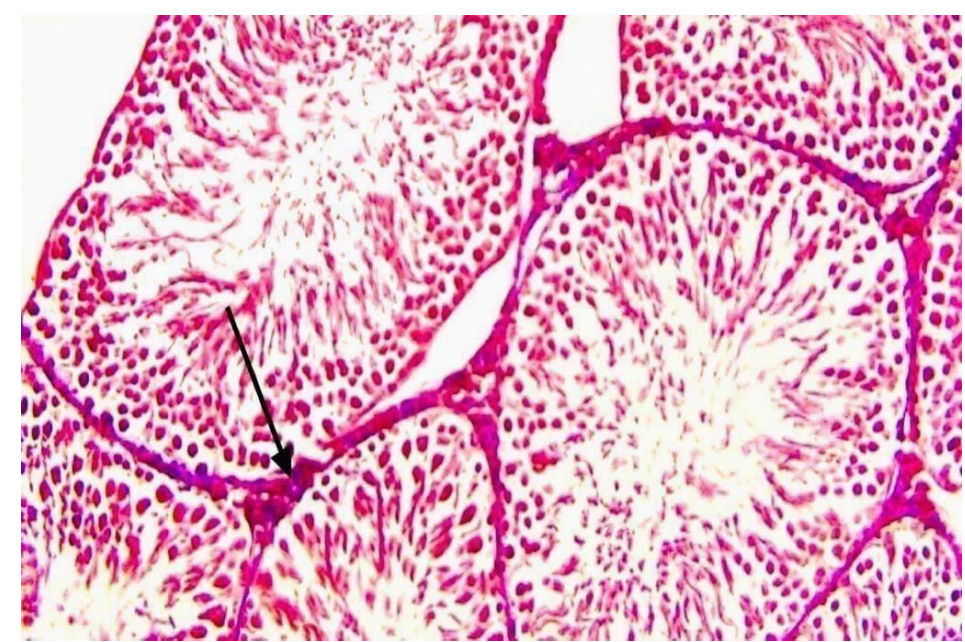

Fig. (11) A photomicrograph of section of adult rat testis of Se group showing: few amount of collagen fibers in the interstitial tissue between the seminefrous tubules which appear blue in color (black arrow). (Masson trichrome x200)

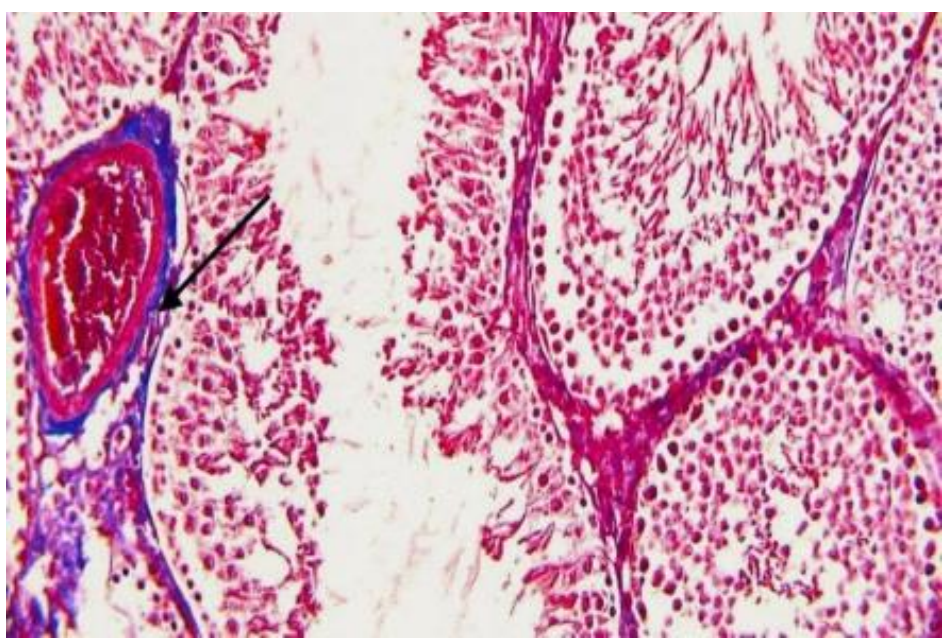

Fig. (12) A photomicrograph of section of adult rat testis of BPA group showing: increased amount of collagen fibers around dilated and congested blood vessel and in the interstitial tissue between the seminefrous tubules which appear blue in color (black arrow).(Masson trichrome x200) 


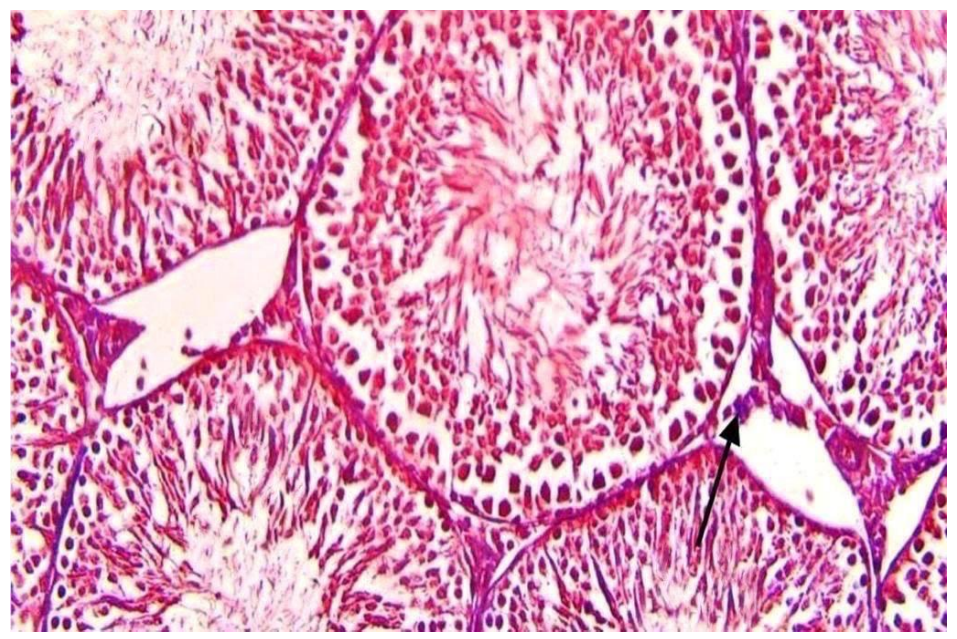

Fig. (13) A photomicrograph of section of adult rat testis of BPA +Se group showing: few amount of collagen fibers in the interstitial tissue between the seminefrous tubules which appear blue in color (black arrow). (Masson trichrome x200)

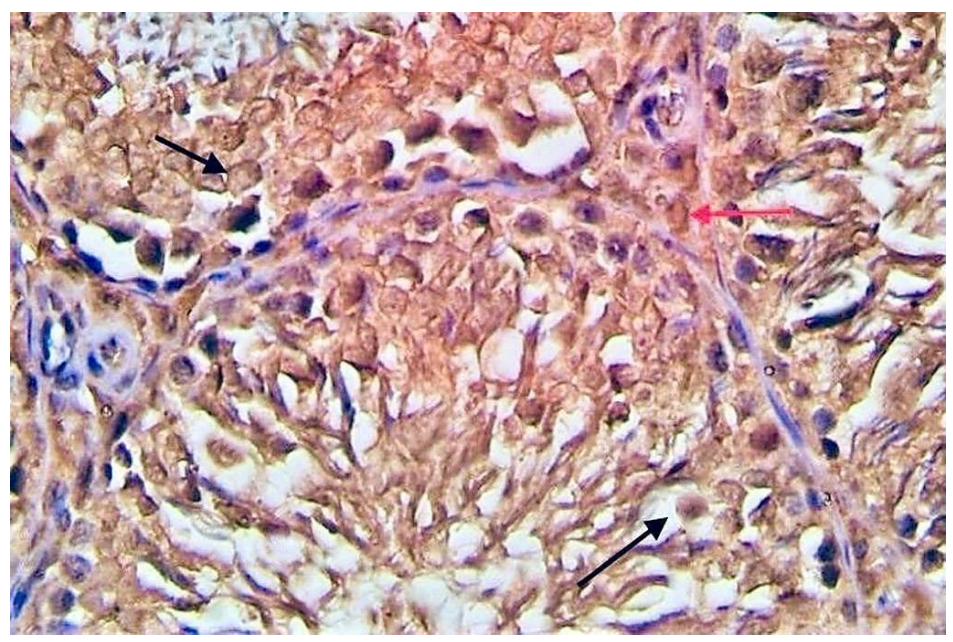

Fig. (14) A photomicrograph of section of adult control rat testis showing: intense positive Bcl-2 immunoreaction which appear as brown cytoplasmic pigmentation in cells lining the seminiferous tubule (black arrow) and in the interstitial tissue in between (red arrow). (BCL2 immunestaining x400)

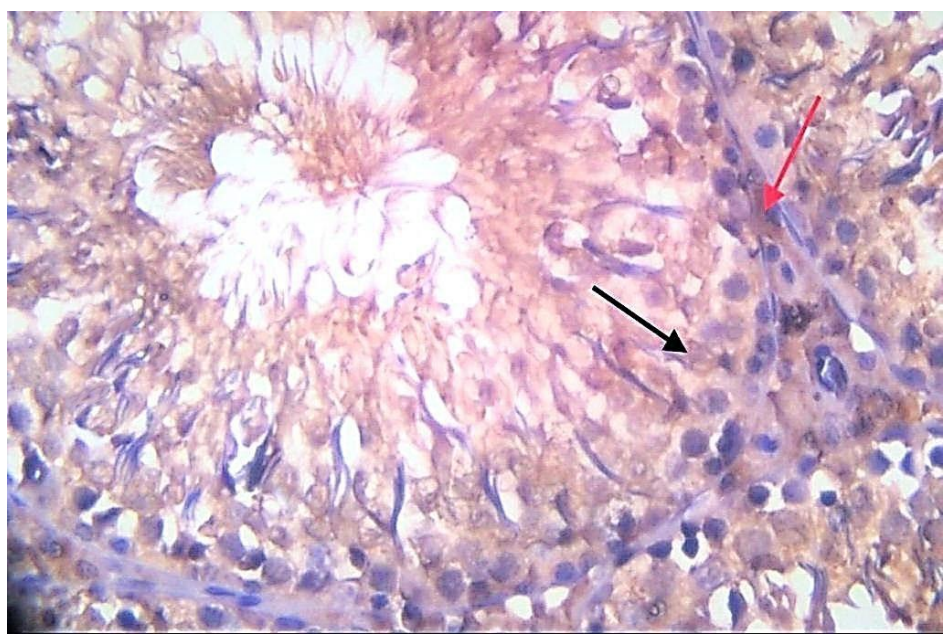

Fig. (15) A photomicrograph of section of adult rat testis of Se group showing: intense positive Bcl-2 immunoreaction which appear as brown cytoplasmic pigmentation in cells lining the seminiferous tubule (black arrow) and in the interstitial tissue in between (red arrow). (BCL2 immunestaining x400) 


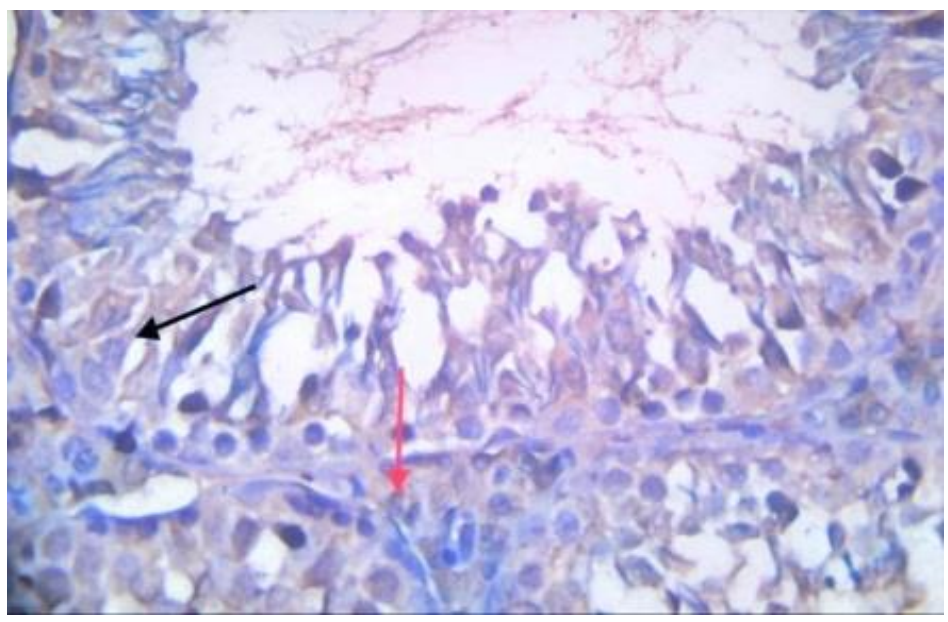

Fig. (16) A photomicrograph of section of adult rat testis of BPA group showing: minimal positive Bcl-2 immunoreaction which appear as light brown cytoplasmic pigmentation in cells lining the seminiferous tubule (black arrow) and in the interstitial tissue in between (red arrow). (BCL2 immunestaining x400)

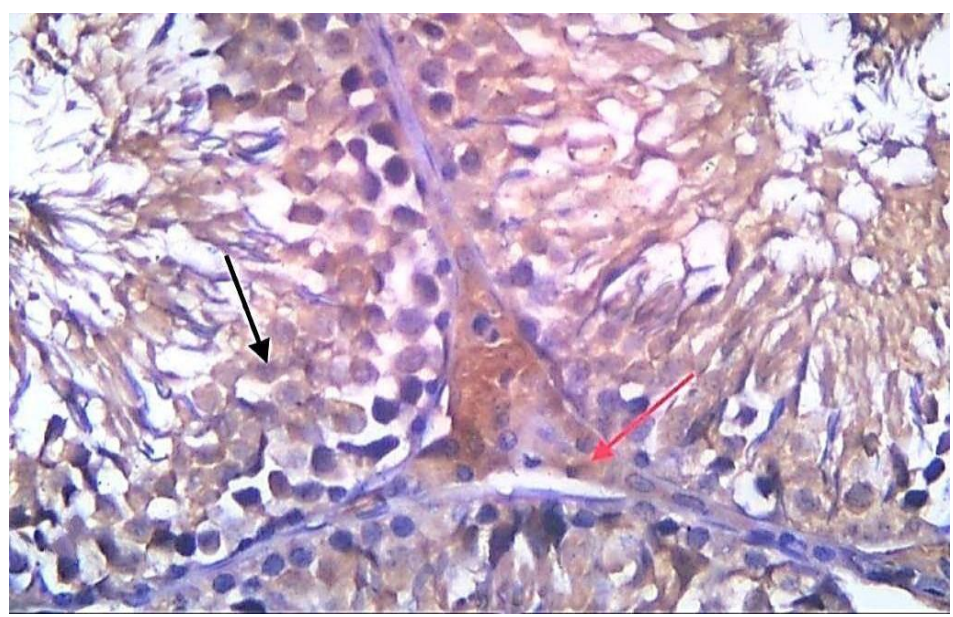

Fig. (17) A photomicrograph of section of adult rat testis of BPA +Se group showing: intense positive Bcl-2 immunoreaction which appear as brown cytoplasmic pigmentation in cells lining the seminiferous tubule (black arrow) and in the interstitial tissue in between (red arrow). (BCL2 immunestaining x400)

Table (1) showing mean values of area percent of collagen fibers deposition \pm SD in the 4 studied groups

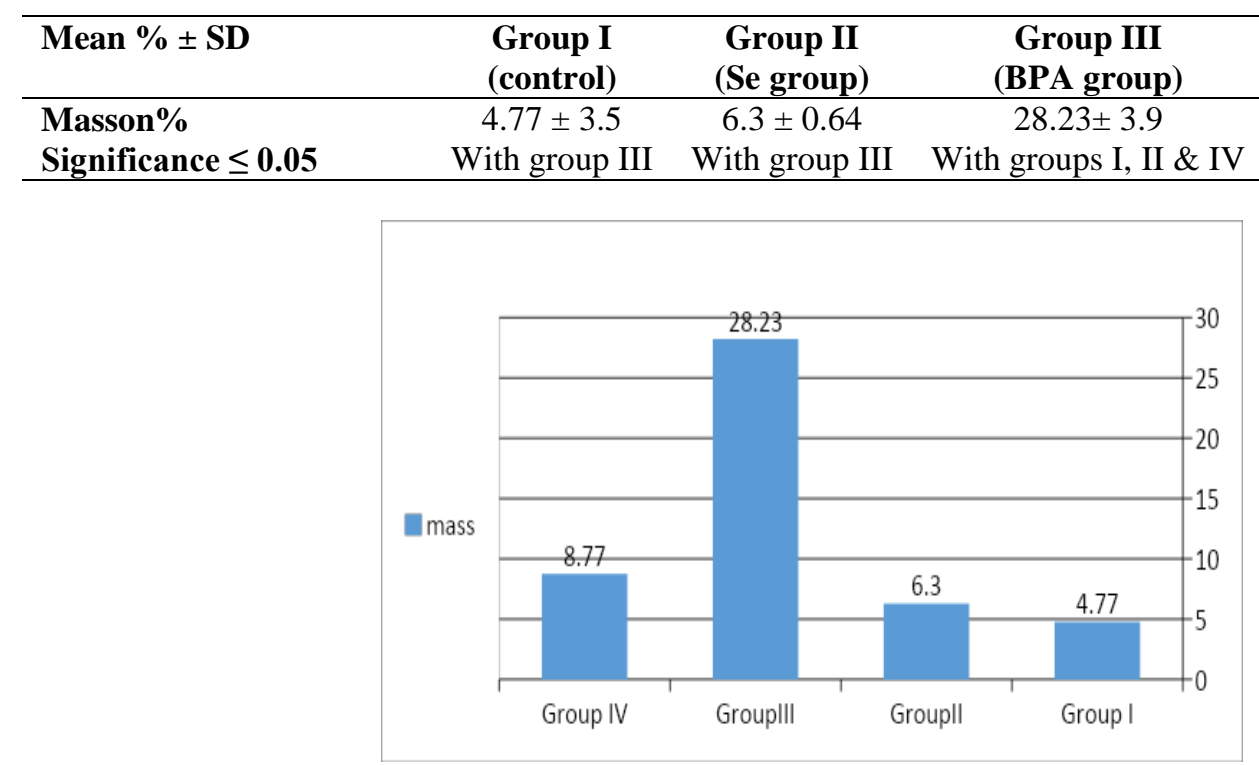

Histogram (1) showing values of area percent of collagen fibers deposition in the 4 studied groups. 
Table (2) showing mean values of area percent immunoreactivity of BCL2 \pm SD in the 4 studied groups.

\begin{tabular}{lcccc}
\hline Mean \% \pm SD & $\begin{array}{c}\text { Group I } \\
\text { (Control) }\end{array}$ & $\begin{array}{c}\text { Group II } \\
\text { (Se group) }\end{array}$ & $\begin{array}{c}\text { Group III } \\
\text { (BPA group) }\end{array}$ & $\begin{array}{c}\text { Group IV } \\
\text { (BPA+Se group ) }\end{array}$ \\
\hline MA(Mean Area) & $54.2 \pm 4.6$ & $52.9 \pm 6.2$ & $7.4 \pm \mathbf{7 . 9}$ & $40.6 \pm 3.8$ \\
Significance $\leq \mathbf{0 . 0 5}$ & With group III &. & With groups I, II \& IV & With group III \\
\hline
\end{tabular}

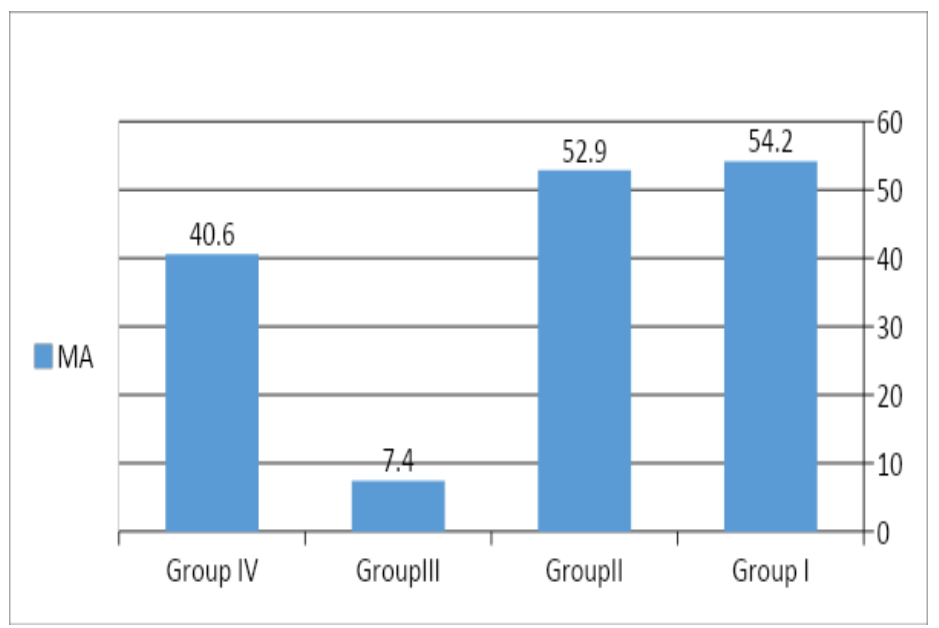

Histogram (2) showing mean values of area percent of BCL2 immunoreactivity in the 4 studied groups.

\section{Discussion}

In the current study, the lumen of seminiferous tubules was nearly empty from mature sperms, which is consistent with ElGendy et al., [11] who reported that the degenerative changes in Leydig cells can disrupt normal function and lead to a decrease in androgen production, which can have a negative impact on spermatogenesis. BPA and its analogues also have antiandrogenic characteristics, but they also generate oxidative stress, which affects adult reproductive function, according to Ullah et al. [12]. It was also shown that when male rats were exposed to environmental BPA, the quantity of spermatocytes, spermatogonia, as well as the testosterone concentration may be lowered. [14], according to Kazemi et al. As a result of BPA's action on the P450 cytochrome, which is a key enzyme in the manufacture of testosterone in Leydig cells, testosterone levels may decline. Also Abdel-Halim et al. [15], who observed that rats treated with BPA dramatically lowered the percentage of living sperm and increased sperm cell abnormalities. Oxidative stress and damage to DNA caused by BPA during spermatogenesis may be to blame for these problems. This study also found that the seminiferous epithelium had degenerated, which is consistent with ElGendy et al., [11] who explained this by the fact that the seminiferous tubules are avascular, which means that all oxygen and nutrients exit the interstitial space and enter the Sertoli cells, where they reach the germ cells. Because of this, they are on the brink of hypoxia, which may make them very vulnerable to BPA. Necrotic spermatocytes and elongated spermatids were found inside the tubules, which is in keeping with the findings of Vijaykumar et al. [16], who found sloughing of cells into the lumen and a reduction in the number of germ cells in the research. A study done by Fawzy and his colleagues found that the testicular tissue of the group given BPA showed an obvious defective spermatogenesis that was marked by severe necrosis and the loss of the spermatogonial layers, and that multiple spermatid giant cells formed in the majority of the seminiferous tubules. [17]." The germinal epithelium of the seminiferous tubules was observed to be separated in this study, which was in agreement with the findings of Alboghobeish et al. [18] and Othman et al. [19]. Some endocrine disruptors, such as BPA, may produce oxidative stress, according to El Ghazzawy et al. [20]. Munir et al. [21] found that BPA-induced oxidative stress was connected to male infertility. LPO levels rose significantly after exposure to BPA.

GSH (Glutathione) and SOD (Superoxide dismutase) levels in the testis and epididymis were significantly decreased in the presence of lipid peroxidation. Leydig cells' steroidogenic capability and the germinal epithelium's ability to distinguish normal spermatozoa may be disrupted by oxidative stress in the testicles. In rats, BPA has been shown to cause testicular toxicity, as reported by Tiwari and Vanage (Tiwari and Vanage, 2014). [22]. Vacuolation and exudate fluid in the interstitium were found in this study, which was in agreement with the findings of (Mohamed and Arafa, 23); Kamel et al., [11] and Tolba and Mandour [24] who reported that one of the constant pathological changes found in all tested reproductive organs was dilation and congestion of the interstitial blood vessels.. An increase in adenosine synthesis leads blood vessels to dilate and increase blood flow to restore the oxygen ratio to its normal level, which causes the dilation of blood vessels and an 
increase in blood flow. BPA group slices treated with masson trichrome exhibited a higher concentration of collagen fibers surrounding blood vessels. For our findings, we relied on morphometric and statistical data, which showed that the mean area percentage of collagen fibres deposition in the BPA group was significantly higher than that in the Se group (P 0.05). They found that the masson's trichrome stained sections of the Bisphenol-A-treated group showed a large amount of the collagen fibres around the dilated congested blood vessels in the testis, epididymis, prostate, and seminal vesicles of the testis, epididymis, and prostate of the Bisphenol-A-treated group. There was a minimal positive cytoplasmic reaction in the form of light brown pigmentation in the cytoplasm of cells lining the seminefrous tubules and in the interstitial tissue stained by Bcl-2 immunohistochemical examination of BPA-treated testicular sections. Bcl-2 immuno-expression in the testes and semen of rats exposed to BPA had decreased significantly compared to the control group, Se, and these findings were confirmed by Othman and colleagues [19] who found that the number of apoptotic cells and necrotic cells in BPA-treated rats was significantly higher than in controls. Bcl-2 levels in the same cells were found to be significantly reduced, supporting these findings. BPA-induced oxidative stress is thought to have caused apoptosis in germ cells. In addition, Chianese et al.,[27] and Jin et al.,[28] demonstrated that low-dose BPA causes germ cell apoptosis through the up-regulation of Bax and the down-regulation of $\mathrm{Bcl}-2$, which are both members of the Bcl-2 family. Bcl-2 proteins have an antiapoptotic effect, and Bax has been shown to promote apoptosis in the body.. Moreover, BPA exposure has been linked to a decrease in cell proliferation, an increase in ROSmediated damage and an increase in apoptosis of male gametes by inhibiting Bcl-2 and activating Caspase 3 apoptosis pathways. In this study, the histological Examination of H\&E stained sections of the testes of the BPA+Se group showed significant improvement in the histological structure of the testis and the architecture of seminiferous tubules were nearly similar to normal.

The seminiferous tubules were densely packed and lined with intact stratified germinal epithelium and no degeneration was seen. The seminiferous epithelium appeared adherent to the basal laminae and no separation was seen and these results are in agreement with kaur et al.,(2018) who found that dietary selenium supplementation reduced ROS levels. (Reactive Oxygen Species) and (LPO) lipid peroxidation in mouse testes and histopathological changes were lessened, protecting the basement membrane and decreasing the vacuolization of germ cells. GSH-Px (Glutathione Peroxidase), a scavenging enzyme for reactive oxygen species, is likely to be responsible for this impact. And Ahmed Zaki et al. (2020) claimed that the testicular structure of the group given BPA with Se improved considerably compared to the group given just BPA. CAT, SOD, and GSH-Px activities all increased as a consequence of the Se, as did MDA (Malondialdehyde), an oxidative stress marker. As a consequence, the testicles were shielded from oxidative damage. It was also shown that Se supplementation may boost the activity of enzymes such as GPx that need it. Before they may harm the body, peroxides are broken down by this enzyme. To some extent, this may reduce free-radical-mediated LPO and increase testicular antioxidant status. There were just a few collagen fibres in the interstitial tissue between the seminefrous tubules stained with masson trichrome in this research.

According to morphometric and statistical data, we found that the mean area percentage of collagen fibres deposition ( $P$ 0.05) decreased significantly in the $\mathrm{BPA}+\mathrm{Se}$ group as compared to the BPA group (Table 1). Testicular collagen fibre deposition in the BPA+Se group did not vary significantly from that in the control or Se groups $(\mathrm{P}>0.05)$. Mohamed and Rateb, (2019) revealed that the group administered both BPA and se showed low deposition of collagen in masson trichrome sections of the thyroid gland compared to that in the BPA group. Both BPA and Se were shown to have a substantial impact on lung damage and fibrosis reduction in Abedelhaffez et al., (2017). This study found a strong positive cytoplasmic response in the form of brown pigmentation in the cytoplasm of cells lining the seminefrous tubules and interstitial tissue in BPA+Se treated testicular sections stained by $\mathrm{Bcl}-2$. A significant increase in $\mathrm{Bcl}-2$ immunoexpression (P 0.05) was found in the BPA+Se group compared to the BPA group, and there was no significant difference in the mean area percentage of $\mathrm{Bcl}-2$ immuno-expression ( $\mathrm{P}$ 0.05) in the $\mathrm{BPA}+\mathrm{Se}$ group compared to the control group, Se group, according to morphometric and statistical results. These findings were in agreement with kaur et al.,(30) who reported that Se had no effect on Bcl-2 immunoexpression. It has been shown that BPA may promote lipid peroxidation and lower testosterone levels in the body. Because of this, low testosterone levels in the testicles may lead to the detachment of germ cells from the seminiferous epithelium. Apoptosis in male germ cells may be induced by many methods. Antioxidant effects were offset by Se, which also enhanced the stress response in rats exposed to BPA.

\section{Conclusions}

The findings of this study show that BPA has a negative influence on the anatomy of the testicles in adult male rats. Adult male rat testis are protected against the damaging effects of BPA by Se.

\section{References}

[1] C.Desdoits-Lethimonier, L.Lesné, P.Gaudriault, D.Zalko, J.P.Antignac, Y.Deceuninck, and B.Jégou, Parallel assessment of the effects of bisphenol $\mathrm{A}$ and several of its analogs on the 
adult human testis. Human Reproduction.vol.32(7),pp.1465-1473,2017.

[2] J.Tian, Y.Ding, R.She, L.Ma, F.Du, K.Xia, and L.Chen, Histologic study of testis injury after bisphenol A exposure in mice: Direct evidence for impairment of the genital system by endocrine disruptors. Toxicology and industrial health.vol.33(1),pp.36-45,2017.

[3] K.Pivnenko, G.A.Pedersen, E.Eriksson, and T.F.Astrup, Bisphenol A and its structural analogues in household waste paper. Waste management.vol.44,pp.39-47,2015.

[4] S.Babu, S.N.Uppu, B.Martin, O.A.Agu, and R.M.Uppu, Unusually high levels of bisphenol A (BPA) in thermal paper cash register receipts (CRs): development and application of a robust LC-UV method to quantify BPA in CRs. Toxicology mechanisms and methods.vol.25(5),pp.410-416,2015.

[5] F.Vahdati Hassani, S.Mehri, K.Abnous, R.Birner-Gruenberger, and H.Hosseinzadeh, Protective effect of crocin on BPA-induced liver toxicity in rats through inhibition of oxidative stress and downregulation of MAPK and MAPKAP signaling pathway and miRNA-122 expression. Food and Chemical Toxicology.vol.107,pp.395-405,2017.

[6] R.P.Mason, A.L.Soerensen, B.P.DiMento, and P.H.Balcom, The global marine selenium cycle: Insights from measurements and modeling. Global Biogeochemical Cycles.vol.32(12),pp.1720-1737,2018.

[7] M.Kieliszek,Selenium-fascinating microelement, properties and sources in food. Molecules.vol.24(7),pp.1298,2019.

[8] M.Kiełczykowska, J.Kocot, M.Paździor, and I.Musik, Selenium-a fascinating antioxidant of protective properties. Adv Clin Exp Med.vol.27(2),pp.245-255,2018.

[9] M.Gupta, and S.Gupta, An overview of selenium uptake, metabolism, and toxicity in plants. Frontiers in plant science.vol.7,pp.2074,2017.

[10] I.Bano, H.Sajjad, MSH.Talpur, A.Leghari and KH.Mirbahar, Role of selenium on oxidative stress and male reproductive system. Pakistan Journal of Biochemical and Molecular Biology.vol.49(4),pp.75-79,2016.

[11] M.M.L.ElGendy, M.A.Rashed, R.A.M.Ali, and A.H.Kamel, Reproductive Toxicity Induced by Low Dose Bisphenol A (BPA) in Male Rats. Journal of Scientific Research in Science, 37(Part 2 (Biological Sciences)),pp.73-98,2020.

[12]A.Ullah, M.Pirzada, S.Jahan, H.Ullah, G.Shaheen, H.Rehman, and M.A.Butt, Bisphenol A and its analogs bisphenol B, bisphenol $\mathrm{F}$, and bisphenol $\mathrm{S}$ : Comparative in vitro and in vivo studies on the sperms and testicular tissues of rats. Chemosphere.vol.209,pp.508-516,2018.
[13] W.M.Al-Amoudi, Antioxidant activity of selenium on bisphenol-induced apoptosis and testicular toxicity of rats. African Journal of Pharmacy and Pharmacology.vol.12(21),pp.278289,2018 .

[14] S.Kazemi, F.Feizi, F.Aghapour, G.A.Joorsaraee, and A.A.Moghadamnia, Histopathology and histomorphometric investigation of bisphenol A and nonylphenol on the male rat reproductive system. North American journal of medical sciences.vol.8(5),pp.215-221,2016.

[15]B.R.Abdel-Halim, A.A.Khalaf, W.A.Moselhy, and W.M.Ahmed, Protective effect of nanoselenium and ionized selenium against the testicular damage, endocrine disruptor and testicular ultrastructure of bisphenol $\mathrm{A}$ in albino male rats. Asian Journal of Animal and Veterinary Advances.vol.11(11),pp.653664,2016

[16]T.Vijaykumar, D.Singh, G.R.Vanage, R.V.Dhumal, and V.D.Dighe, Bisphenol Ainduced ultrastructural changes in the testes of common marmoset. The Indian journal of medical research.vol.146(1),pp.126-137,2017.

[17] E.I.Fawzy, A.I.El Makawy, M.M.El-Bamby, and H.O.Elhamalawy, Improved effect of pumpkin seed oil against the bisphenol-A adverse effects in male mice. Toxicology reports.vol.5,pp.857-863,2018.

[18] S.Alboghobeish, M.Mahdavinia, L.Zeidooni, A.Samimi, A.A.Oroojan, S.Alizadeh, and Khorsandi, L. Efficiency of naringin against reproductive toxicity and testicular damages induced by bisphenol $\mathrm{A}$ in rats. Iranian journal of basic medical sciences.vol.22(3),pp.315$323,2019$.

[19] A.I.Othman, G.M.Edrees, M.A.El-Missiry, D.A.Ali, M.Aboel-Nour, and B.R.Dabdoub, Melatonin controlled apoptosis and protected the testes and sperm quality against bisphenol A-induced oxidative toxicity. Toxicology and Industrial Health.vol.32(9),pp.1537-1549,2016.

[20]I.F.El Ghazzawy, A.E.Meleis, E.F.Farghaly, and A.Solaiman, Histological study of the possible protective effect of pomegranate juice on bisphenol-A induced changes of the caput epididymal epithelium and sperms of adult albino rats. Alexandria Journal of Medicine.vol.47(2),pp.125-137,2011.

[21]B.Munir, A.Qadir, and M.Tahir, Negative effects of bisphenol A on testicular functions in albino rats and their abolitions with Tribulus terristeris L. Brazilian journal of pharmaceutical Sciences.vol.53(3),pp.e00104,2017.

[22]D.Tiwari, and G.Vanage, Bisphenol A induces oxidative stress in bone marrow cells, lymphocytes, and reproductive organs of Holtzman rats. International journal of toxicology.vol.36(2),pp.142-152,2017. 
[23] D.A.Mohamed, and M.H.Arafa, Testicular toxic changes induced by bisphenol $\mathrm{A}$ in adult albino rats: a histological, biochemical, and immunohistochemical study. Egyptian Journal of Histology.vol.36(1),pp.233-245,2013.

[24]A.M.Tolba, and D.A.Mandour, Histological effects of bisphenol-A on the reproductive organs of the adult male albino rat. Eur $\mathbf{J}$ Anat.vol.22(2),pp.89-102,2018.

[25]F.Abd-Elfadeel, O.Y.Ibrahim, M.I.Ali, M.R.Abd El-haleem, and Karima, The Effect of Bisphenol and Octylphenol (plasticizers) on the Testis of Adult Albino Rat (Histological and Immunohistochemical Study). British Journal of Science.vol.15(1),pp.1-31,2017.

[26] A.Fahmy, The Effect of Bisphenol A on The Testis of Adult Male Albino Rats And The Possible Protective Effect of Thymoquinone: A Histological and Immunohistochemical Study. Journal of Cell and Tissue Research.vol.17(1),pp.6021-6034,2017.

[27]R.Chianese, A.Viggiano, K.Urbanek, D.Cappetta, J.Troisi, M.Scafuro, and R.Meccariello, Chronic exposure to low dose of bisphenol A impacts on the first round of spermatogenesis via SIRT1 modulation. Scientific reports.vol.8(1),pp.1-12,2018.

[28]P.Jin, X.Wang, F.Chang, Y.Bai, Y.Li, R.Zhou, and L.Chen, Low dose bisphenol A impairs spermatogenesis by suppressing reproductive hormone production and promoting germ cell apoptosis in adult rats. Journal of biomedical research.vol.27(2),pp.135-144,2013.

[29] Q.Yang, X.Sui, J.Cao, C.Liu, S.Zheng, M.Bao, and K.Wu, Effects of exposure to Bisphenol A during pregnancy on the pup testis function. International journal of endocrinology.Article ID 6785289,pp.1-8,2019.

[30] S.Kaur, M.Saluja, and M.P.Bansal, Bisphenol A induced oxidative stress and apoptosis in mice testes: Modulation by selenium. Andrologia.vol.50(3),pp.e12834,2018.

[31] M.S.Ahmed Zaki, M.A.Haidara, M.Heitham, A.Asim, E.El Sayed Massoud, and R.A.Eid, Antioxidant Activity of Selenium on BisphenolInduced Apoptosis and Testicular Toxicity of Albino Rats. International Journal of Morphology.vol.38(6),pp.1786-1796,2020.

[32]R.Z.Hamza, M.S.Al-Harbi, and N.S.El Shenawy, Ameliorative effect of vitamin E and selenium against oxidative stress induced by sodium azide in liver, kidney, testis and heart of male mice. Biomedicine and Pharmacotherapy.vol.91,pp.602-610,2017.

[33]H.K.Mohamed, and A.Rateb, Histoloical and Biochemichal Study on the Toxic Effects of Bisphenol A on the Thyroid Gland of Adult Male Albino Rats and the Possible Protection by Selenium. Egyptian Journal of Histology.vol.42(3),pp.667-685,2019.
[34] A.S.Abedelhaffez, E.A.Abd El-Aziz, M.A.A.Aziz, and A.M.Ahmed, Lung injury induced by Bisphenol A: A food contaminant, is ameliorated by selenium supplementation. Pathophysiology.vol.24(2),pp.81-89,2017.

[35]S.Kaur, M.Saluja, A.Aniqa, and S.Sadwal, Selenium attenuates bisphenol A incurred damage and apoptosis in mice testes by regulating mitogen-activated protein kinase signalling. Andrologia.vol.53(3),pp.e13975,2021. 